\title{
CHARGE-DISCHARGE MODEL SUPERKAPASITOR RGO DALAM SISTEM ELEKTROLIT KCI
}

\author{
DIYAN UNMU DZUJAH, VIKA MARCELINA, NORMAN SYAKIR, AYI BAHTIAR, \\ FITRILAWATI* \\ Departemen Fisika, FMIPA, Universitas Padjadjaran \\ Jl. Raya Bandung-Sumedang Km.21 Jatinangor 45363, Sumedang, Jawa Barat \\ *email : fitrilawati@phys.unpad.ac.id
}

\begin{abstract}
Abstrak. Reduced Graphene Oxide (RGO) memiliki potensi aplikasi sebagai elektroda superkapasitor. Dalam penelitian ini dikaji karakteristik charge-discharge dari sistem superkapasitor RGO yang menggunakan larutan $\mathrm{KCl}$ sebagai elektrolit. Film tipis Graphene Oxide (GO) dibuat dengan teknik solution casting di atas substrat glass/ITO dari dispersi GO dalam akuades dengan konsentrasi $1 \mathrm{mg} / \mathrm{ml}$. Untuk mendapatkan film RGO maka film GO yang telah dibuat direduksi secara termal di atas hotplate pada suhu $200^{\circ} \mathrm{C}$ selama 1 jam untuk mengurangi kadar oksigen pada film tersebut. Model superkapasitor terdiri dari pasangan film RGO/ITO sebagai elektroda, serta larutan I M $\mathrm{KCl}$ sebagai elektrolit. Untuk melihat karakteristik dari model divais superkapasitor tersebut dilakukan pengujian charge-discharge pada berbagai macam arus discharge.
\end{abstract}

Kata kunci : oksida grafena tereduksi, reduksi termal, model superkapasitor, chargedischarge

\begin{abstract}
Reduced Graphene Oxide (RGO) has potential application as a supercapacitor electrode. We studied charge-discharge characteristic of RGO supercapacitor using $\mathrm{KCl}$ solution as electrolyte. Thin film of Graphene Oxide (GO) was prepared using solution casting technique on glass/ITO substrate from $1 \mathrm{mg} / \mathrm{ml} \mathrm{GO}$ dispersed in water. RGO thin film was obtained from GO film that was thermally reduced on a hotplate at temperature of $200^{\circ} \mathrm{C}$ for 1 hour to remove its oxygen contained. Supercapacitor device model was consist of pair of RGO/ITO films as electrodes, and $1 \mathrm{M} \mathrm{KCl}$ solution as electrolyte. In order to measure characteristic of the supercapacitor device model, we performed chargedischarge measurements at varied discharge current.
\end{abstract}

Keywords : reduced graphene oxide, thermal reduction, supercapacitor model, chargedischarge

\section{Pendahuluan}

Superkapasitor yang juga dikenal sebagai kapasitor elektrokimia merupakan salah satu solusi untuk penyimpanan energi karena memiliki densitas daya dan densitas energi yang tinggi, yaitu sekitar 10 kali lebih besar dibanding kapasitor dan baterai konvensional [1]. Performa superkapasitor bergantung pada elektroda, elektrolit dan kondisi operasinya [2]. Superkapasitor tidak mengalami reaksi kimia seperti pertukaran ion seperti baterei, sehingga dalam kondisi operasi normal dapat stabil hingga ribuan siklus tanpa mengalami degradasi [3]. Superkapasitor dapat memiliki densitas daya yang tinggi yaitu sekitar $10^{3}-10^{4} \mathrm{~W} / \mathrm{Kg}$ karena memiliki elektroda yang luas permukaannya besar namun memiliki jarak antar ion yang rendah pada antarmuka double layer $[4,5]$. 
Di antara meterial karbon, grafena merupakan material yang paling menjanjikan sebagai elektroda untuk aplikasi divais penyimpanan energi karena memiliki luas permukaan yang tinggi, relatif murah, memiliki konduktivitas listrik yang tinggi [6,7]. Material ini memiliki mobilitas elektron sebesar $15.000 \mathrm{~cm}^{2} / \mathrm{V} \cdot \mathrm{s}$, konduktivitas termal sebesar $5.000 \mathrm{Wm}^{-1} \mathrm{~K}^{-1}$ [8]. Grafena merupakan material ideal untuk fabrikasi superkapasitor karena memiliki luas permukaan yang besar yaitu $2630 \mathrm{~m}^{2} / \mathrm{g}$ [5,9] dan kapasitansi elektrokimia intrinsik sebesar $\sim 21 \mathrm{~m} \mathrm{~F} / \mathrm{cm}^{2}$. Nilai tersebut merupakan nilai maksimum untuk semua material berbasis karbon) [10]. Namun untuk aplikasi, jumlah material grafena sangat sedikit dan tidak memadai. Sebagai aternatif grafena dapat digunakan reduced graphene oxide (rGO) yang diperoleh dengan cara mereduksi graphene oxide (GO) dengan cara melepaskan kandungan gugus oksigen yang masih menempel. Karakteristik struktur, sifat listrik dan mekanik dari rGO hampir sebanding dengan grafena. Selain itu, rGO dapat disintesis dari grafit menggunakan teknik sederhana sehingga biaya pembuatan material rGO jauh lebih kecil dibandingkan dengan material grafena murni [11].

Pada penelitian ini dibuat model divais superkapasitor dengan menggunakan reduced graphene oxide ( $\mathrm{rGO}$ ) sebagai elektroda dan $\mathrm{KCl}$ sebagai elektrolit. Pemilihan elektrolit $\mathrm{KCl}$, mempertimbangkan kondisi bahwa elektrolit yang banyak dipakai seperti $\mathrm{H}_{2} \mathrm{SO}_{4}, \mathrm{HCl}$, bersifat asam dan memiliki sifat korosif sehingga dapat merusak sistem divais, terutama bila terjadi kebocoran. Pada penelitian sebelumnya telah dibuat model superkapasitor rGO yang menggunakan elektrolit $\mathrm{H}_{2} \mathrm{SO}_{4}$ dan sudah menunjukkan karakteristik penyimpanan muatan [12]. Hal tersebut mendorong pembuatan model superkapasitor dengan alternatif elektrolit selain asam atau basa, yaitu elektrolit garam berupa $\mathrm{KCl}$.

\section{Metode Penelitian}

Pembuatan film tipis rGO diawali dengan penyiapan substrat ITO dan sonikasi dispersi GO menggunakan ultrasonic bath pada suhu ruang. Substrat ini dicuci dengan menggunakan teepol, lalu disonikasi dalam ultrasonic bath selama 15 menit pada suhu $50^{\circ} \mathrm{C}$ dengan aquades dan ethanol secara bergantian. Pengeringan permukaan menggunakan air compressor. Film GO dideposisi pada substrat ITOglass menggunakan $1 \mathrm{mg} / \mathrm{ml}$ dispersi GO dalam mili-Q water dengan metode solution-casting. Film tipis yang terbentuk diatas substrat tersebut dikenakan proses annealing selama 5 menit diatas hotplate dengan suhu $30^{\circ} \mathrm{C}$ untuk menghilangkan sisa pelarutnya. Film GO selanjutnya dikenakan proses reduksi secara termal melalui pemanasan pada suhu $200^{\circ} \mathrm{C}$ selama 1 jam di atas hotplate.

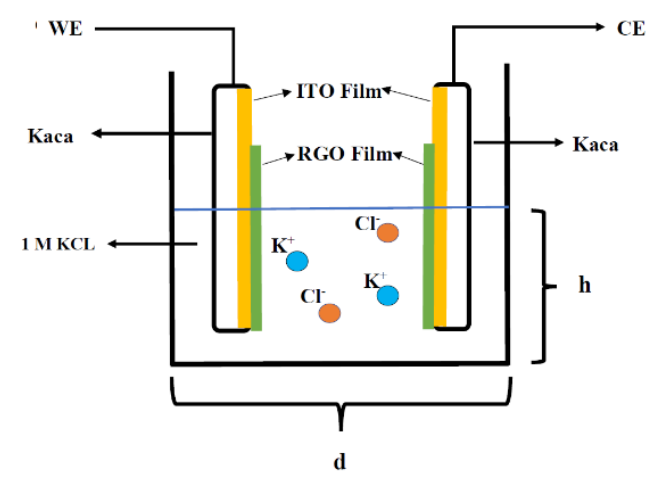

Gambar 1. Model Sel Superkapasitor (RGO-ITO/KCl/ RGO-ITO) 
Model divais superkapasitor terdiri dari pasangan rGO/ITO dan rGO/ITO sebagai elektroda dan $1 \mathrm{M} \mathrm{KCl}$ sebagai elektrolit. Konfifurasi dari model divais superkapasitor tersebut diperlihatkan pada Gambar 1. Karakterisasi chargedischarge (pengisian-pengosongan) dilakukan secara galvanostatik dilakukan pada rentang tegangan $0 \mathrm{~V}$ sampai dengan 0,9 Volt dengan arus pengisian dan pengosongan sebesar $0,1 \mathrm{~mA}, 0,2 \mathrm{~mA}$, dan $0,3 \mathrm{~mA}$.

\section{Hasil dan Pembahasan}

Secara visual film GO yang dideposisi pada substrat ITO tampak kecoklatan. Setelah direduksi tampak bahwa warna film rGO berubah menjadi lebih gelap dibandingkan dengan film GO. Lepasnya gugus oksigen setelah direduksi pada film rGO tersebut menyebabkan atom karbon yang semula berikatan dengan oksigen kembali berikatan dengan atom karbon lainnya dan membentuk konjugasi seperti pada model molekul grafena. Ketika film rGO membentuk konjugasi, maka sifatnya akan seperti logam dan bersifat menyerap sehingga memiliki absorbansi yang lebih tinggi. Warna film rGO yang tampak lebih gelap tersebut mengindikasikan bahwa film rGO tersebut menjadi lebih konduktif dibandingkan dengan film GO. Secara kuantitatif perubahan warna tersebut diperlihatkan oleh perbandingan spektrum UV-Vis film GO/ITO dan film rGO/ITO seperti pada Gambar 2. Kurva tersebut menunjukkan film rGO-ITO memiliki absorbansi yang lebih tinggi disbanding dengan film GO/ITO.

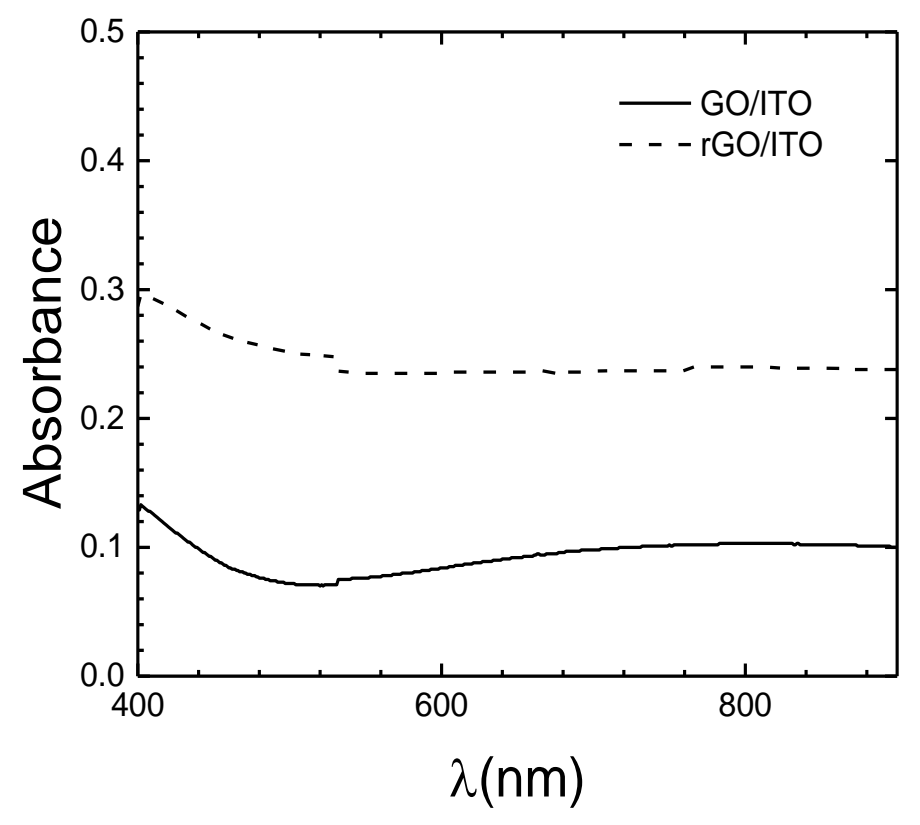

Gambar 2. Perbandingan spektrum UV-Vis film GO dan film RGO pada substrat ITO

Model divais superkapasitor dengan konfigurasi sel (ITO/rGO/KCl/rGO/ITO) seperti Gambar 1 memperlihatkan karakteristik penyimpanan seperti yang diperlihatkan oleh kurva charge-discharge. Kurva charge-discharge dari model divais superkapasitor tersebut berbentuk segitiga seperti yang diperlihatkan pada Gambar 3. Kurva tersebut merupakan cuplikan dari salah satu siklus pengisianpengosongan. Bentuk kurva tersebut menunjukkan model divais superkapasitor 
tersebut dapat melakukan pengisian muatan dan pengosongan muatan dan bersifat reversibel. Dengan demikian kurva tersebut memperlihatkan bahwa divais (ITO/rGO/KCl/rGO/ITO) yang dibuat dapat bekerja sebagai kapasitor karena bisa menyimpan dan mengeluarkan muatan.

Kurva charge-discharge pada Gambar 3 memperlihatkan pada arus pengisian 0,1 $\mathrm{mA}$, untuk mengisi rentang tegangan dari $0 \mathrm{~V}$ sampai $0,9 \mathrm{~V}$ diperlukan waktu $\left(\mathrm{T}_{\mathrm{c}}\right)$ sebesar 31 detik. Pada arus pengosongan yang sama yaitu $0,1 \mathrm{~mA}$ diperlukan waktu $\left(\mathrm{T}_{\mathrm{d}}\right)$ sekitar 24 detik sehingga tegangan turun dari $0.9 \mathrm{~V}$ menjadi $0 \mathrm{~V}$. Tampak pula bahwa ketika arus pengisian dan pengosongan diperbesar, rentang waktu pengisian dan pengosongan menjadi lebih kecil. Nilai Td dan Tc untuk beberapa harga arus pengisian dan pengosongan diperlihatkan pada Tabel 1. Nilai-nilai tersebut menunjukkan waktu yang dibutuhkan untuk pengisian dan pengosongan semakin cepat apabila arus pengisian dan pengosongannya semakin besar.

$$
C=i \frac{\Delta t}{m \Delta V}
$$

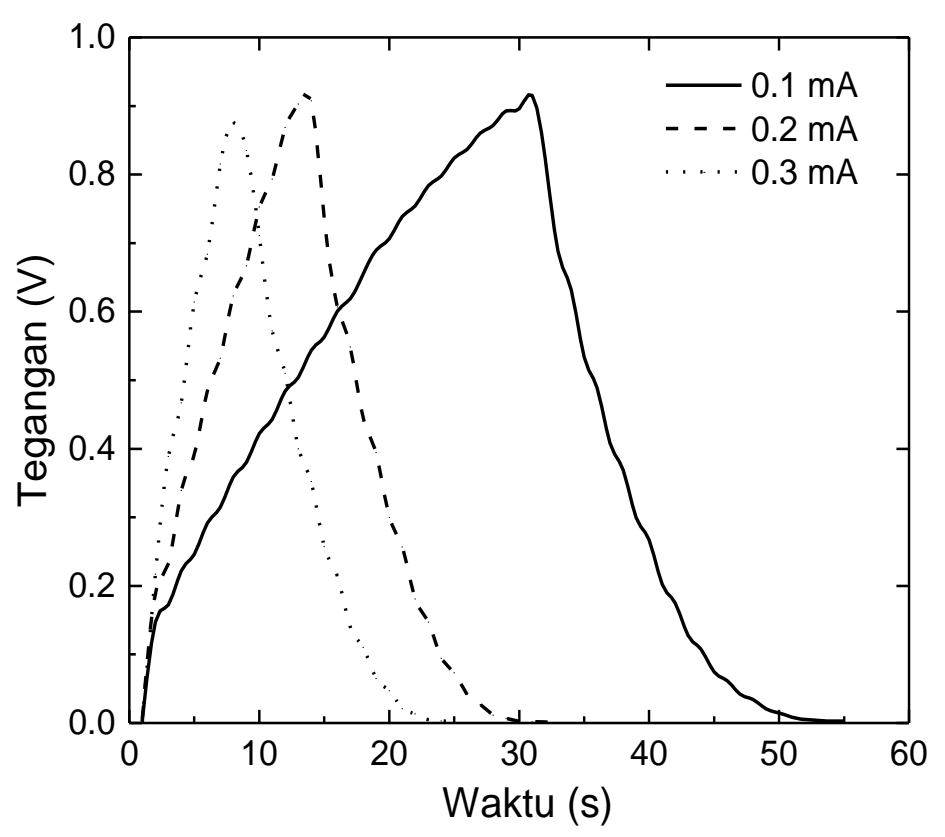

Gambar 3. Kurva Charge-Discharge model superkapasitor (ITO/rGO/KCl/rGO/ITO) dengan berbagai arus pengisian dan pengosongan

Kurva charge-discharge juga digunakan untuk mengestimasi nilai kapasitansi C model superkapasitor yang dibuat dengan menggunakan persamaan (1), dengan $\mathrm{i}=$ arus pengosongan, $\Delta V=$ Lebar tegangan, $\Delta t=$ waktu pengosongan, $\mathrm{m}=$ massa material aktif elektroda. Besar nilai kapasitansi yang dihasilkan diperlihatkan pada Tabel 1. Kapasitansi spesifik dapat dihitung apabila besar massa elektroda rGO yang digunakan dapat diketahui. Besar kapasitansi untuk nilai arus pengosongan yang berbeda tampak berbeda padahal seharusnya sekitar sama. Kondisi tersebut mungkin berkaitan dengan terlalu besarnya besar arus pengosongan yang digunakan. Hasil pengukuran tersebut telah menggambarkan prisnsip kerja model 
divais superkapasitor yang dapat menyimpan muatan. Beberapa perbaikan mesti dilakukan untuk meningkatkan performa model divais yang dibuat.

Tabel 1. Waktu pengisian dan pengosongan serta estimasi kapasitansi model superkapasitor (ITO/rGO/KCl/rGO/ITO)

\begin{tabular}{cccccc}
\hline No & Arus (mA) & $\begin{array}{c}\text { Tegangan } \\
(\mathbf{V})\end{array}$ & $\begin{array}{l}\text { Tc } \\
(\mathbf{s})\end{array}$ & $\begin{array}{l}\text { Td } \\
(\mathbf{s})\end{array}$ & Kapasitansi (mF) \\
\hline 1 & 0,1 & $0-0,9$ & 31 & 24 & 2,67 \\
2 & 0,2 & $0-0,9$ & 14 & 19 & 4,22 \\
3 & 0,3 & $0-0,9$ & 6 & 16 & 5,33 \\
\hline
\end{tabular}

\section{Kesimpulan}

Model divais superkapasitor (ITO/rGO/KCl/rGO/ITO) yang dibuat telah menunjukkan karakteristik penyimpanan muatan. Waktu pengisian dan pengosongan superkapasitor dipengaruhi oleh besar arus yang digunakan. Semakin kecil arus pengisian dan pengosongan maka waktu yang diperlukan untuk pengisian dan pengosongan superkapasitor semakin lama. Kapasitansi model kapasitor model kapasitor yang dibuat dapat diestimasi melalui kurva charge-discharge.

\section{Ucapan terima kasih}

Penelitian ini didanai oleh Proyek Penelitian Unggulan Perguruan Tinggi (PUPT) no kontrak: 718/UN6.3.1/PL/2017 17 April 2017.

\section{Daftar Pustaka}

1. H. Al-Sheikh, N. Moubayed, Proc. Of ACTEA'12 (2012) 257

2. R, Vellacheri, et al, Nano Energy 8 (2014) 231

3. D. Linzen, S. Buller, E. Karden, R.W. De Doncker, IEEE Trans. Ind. Appl. 41 (2005) 1135

4. A.G. Pandolfo, A.F. Hollenkamp, J. Power Sources 157 (2006) 11

5. L.L. Zhang, X.S. Zhao, Chem. Soc. Rev. 38 (2009) 2520

6. M.D. Stoller, S. Park, Y. Zhu, J. An, R.S. Ruoff, Nano Lett. 8 (2008) 3498

7. L.L. Zhang, X.S. Zhao, Chem. Soc. Rev. 38 (2009) 2520

8. B. Y. Zhu, S. Murali, W. Cai, X. Li, J. W. Suk, J. R. Potts, and R. S. Ruoff, Adv. Mater 22 (2010) 3906

9. B.E. Conway, Electrochemical Supercapacitors: Scientific Fundamentals and Technological Applications, Springer Science \& Business Media, 2013

10. R. K, M. Carlen, Electrochim. Acta 45 (2000) 2483

11. J. Shen, K. Han, E.J. Martin, Y.Y. Wu, M.C. Kung, C.M. Hayner, K.R. Shull, H.H. Kung, J. Mater. Chem. A 2 (2014) 18204

12. Vika Marcelina, Fitri Yuliasari, Yeni W Hartati, Fitrilawati, dan Norman Syakir, Jurnal Fisika dan Aplikasinya, 13 (2017) 112. 